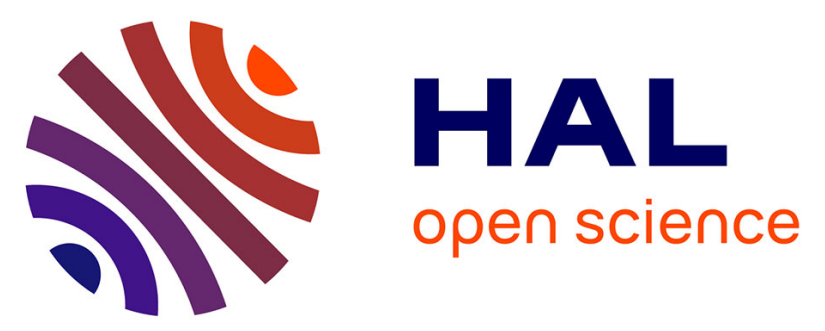

\title{
Enhancement of double-layer capacitance behavior and its electrical conductivity in layered poly (3, 4-ethylenedioxythiophene)-based nanocomposites
}

A. Vadivel Murugan, Annamraju Kasi Viswanath, Guy Campet, Chinnakonda

S. Gopinath, K. Vijayamohanan

\section{To cite this version:}

A. Vadivel Murugan, Annamraju Kasi Viswanath, Guy Campet, Chinnakonda S. Gopinath, K. Vijayamohanan. Enhancement of double-layer capacitance behavior and its electrical conductivity in layered poly (3, 4-ethylenedioxythiophene)-based nanocomposites. Applied Physics Letters, 2005, 87 (24), 243511 (3 p.). 10.1063/1.2140468 . hal-00018703

\section{HAL Id: hal-00018703 https://hal.science/hal-00018703}

Submitted on 9 Feb 2022

HAL is a multi-disciplinary open access archive for the deposit and dissemination of scientific research documents, whether they are published or not. The documents may come from teaching and research institutions in France or abroad, or from public or private research centers.
L'archive ouverte pluridisciplinaire HAL, est destinée au dépôt et à la diffusion de documents scientifiques de niveau recherche, publiés ou non, émanant des établissements d'enseignement et de recherche français ou étrangers, des laboratoires publics ou privés. 


\title{
Enhancement of double-layer capacitance behavior and its electrical conductivity in layered poly (3, 4-ethylenedioxythiophene)-based nanocomposites
}

\author{
A. Vadivel Murugan ${ }^{a}$ \\ Nanocrystalline Materials Group, Centre for Materials for Electronics Technology (C-MET), Off-Pashan \\ Road, Panchawati, Pune-411008, India \\ Annamraju Kasi Viswanath \\ Photonics and Advanced Materials Group, Centre for Materials for Electronics Technology (C-MET), \\ Off-Pashan Road, Panchawati, Pune-411008, India \\ Guy Campet \\ Institut de Chimie de la Matière Condensée de Bordeaux (ICMCB), CNRS, 87 Avenue du Dr. \\ A Schweitzer, 33608 Pessac, France \\ Chinnakonda S. Gopinath \\ Catalysis Division, National Chemical Laboratory, Pune 411 008, India \\ K. Vijayamohanan ${ }^{\text {b) }}$ \\ Physical and Materials Chemistry Division, National Chemical Laboratory, Pune 411 008, India
}

(Received 23 May 2005; accepted 11 October 2005; published online 8 December 2005)

\begin{abstract}
In this letter, we report on the enhanced double-layer capacitance of a layered poly (3, 4-ethylene dioxythiophene) PEDOT- $\mathrm{MoO}_{3}$ nanocomposite, which has been synthesized by a novel microwave irradiation method. The X-ray photoelectron spectroscopy analysis shows the changes in electron density and the shift in binding energy suggesting charge transfer from sulfur atoms upon PEDOT intercalation between $\mathrm{MoO}_{3}$ layers. The room-temperature conductivity for the $\mathrm{PEDOT}-\mathrm{MoO}_{3}$ composite is found to be $1.82 \times 10^{-1} \mathrm{~S} \mathrm{~cm}^{-1}$, which is four orders of magnitude higher than that of the pristine oxide $\left(3.78 \times 10^{-5} \mathrm{~S} \mathrm{~cm}^{-1}\right)$. The enhanced double-layer capacitance of the PEDOT$\mathrm{MoO}_{3}$ nanocomposite $\left(\sim 300 \mathrm{~F} \mathrm{~g}^{-1}\right)$ compared to that $\left(\sim 40 \mathrm{mF} \mathrm{g}^{-1}\right)$ of pristine $\mathrm{MoO}_{3}$ is attributed to higher electronic conductivity, enhanced bidimensionality, and increase in surface area of the nanocomposite. (C) 2005 American Institute of Physics. [DOI: 10.1063/1.2140468]
\end{abstract}

There is much attraction about mounting power sources on semiconductor tips because of the rapid growth of wireless communications and emerging integrated optoelectronic circuits in recent years. For example, electrochemical supercapacitors enable them to be useful in several applications ranging from lightweight electronic fuses, memory back-up power sources, and surge protection devices to pulse power sources for smart weapons. ${ }^{1,2}$ Several conducting polymers and transition metal oxides have been investigated as electrodes for supercapacitors. ${ }^{1-6}$ Among them, amorphous ruthenium oxide $\mathrm{RuO}_{2} \cdot x \mathrm{H}_{2} \mathrm{O}$ exhibits a high specific capacitance of $720 \mathrm{~F} / \mathrm{g} .{ }^{2,7}$ Unfortunately, ruthenium is expensive and hence a considerable reduction in the cost of electrode materials is needed to make the supercapacitor technology, commercially viable. Several strategies have been pursued in this regard including the commonly employed method of dispersion of ruthenium oxide in other less expensive oxide/ carbon matrices. ${ }^{8}$ Similarly, a variety of other methods for producing composites of redox pseudocapacitive materials [polypyrrole, polyaniline, poly( $p$-phenylenevinylene) and polythiophene with ruthenium oxide] and double layer capacitive materials (activated carbon, carbonblack, carbon aerogel, and carbon nanotubes) have been attempted to design cheaper supercapacitor materials with improved performance. $^{9-11}$ However, most of these conducting polymer based composites lack adequate chemical stability due

\footnotetext{
${ }^{a)}$ Electronic mail: vadivel12@hotmail.com

${ }^{b)}$ Electronic mail: viji@ems.ncl.res.in
}

to their high propensity for degradation and consequently their cycle life is adversely affected. ${ }^{12}$

Poly (3,4-ethylenedioxythiophene) PEDOT, has been recently found to exhibit unusually superior stability against thermal degradation, redox behavior over relatively wider range of potentials and coupled with its ecofriendly behavior compared to other common conducting polymers makes this very attractive. ${ }^{12,13}$ Indeed, it appears to be one of the most stable conducting polymers currently available and it has been attracting growing interest for several applications. ${ }^{14}$ However, one approach to modify the properties of an inorganic host material is through the intercalation of electronically conducting large guest species into the interlayer van der Waals gap, albeit with some difficulty. Results using many of these nanocomposites suggest that when these organo-inorganic hybrids are combined at the "nanoscale" level, several new properties like enhanced electrochemical storage ability do emerge due to synergistic effects. ${ }^{14,15}$

Although, poly (3,4-ethylenedioxythiophene) PEDOT nanostructures with various transition metal oxides/sulfides have been reported using different methods, ${ }^{15}$ the electrochemical supercapacitor properties of PEDOT-MoO $\mathrm{M}_{3}$ nanocomposite have not been investigated so far. We used molybdenum trioxide due to its inexpensive inherent advantages compared to $\mathrm{RuO}_{2}$ despite its disadvantages such as relatively slow kinetics for Li-ion transport, electronically insulating state upon full oxidation, and poor cycling behavior. ${ }^{16}$ Recently, Whittingham's group has synthesized $\mathrm{MoO}_{3}$ based bronzes with interesting properties. ${ }^{17}$ In one-dimensional 


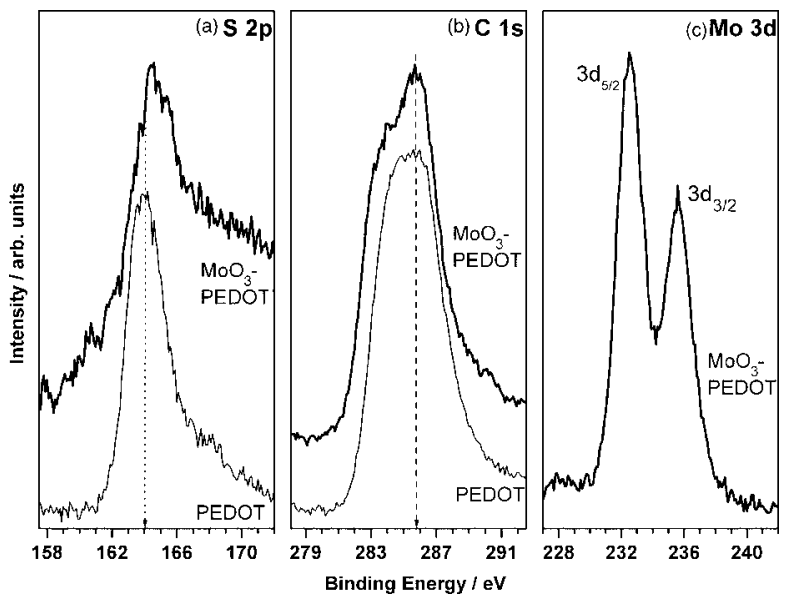

FIG. 1. X-ray photoelectron spectra from (a) $\mathrm{S} 2 p$, (b) C $1 s$, and (c) Mo $3 d$ core levels of PEDOT and PEDOT-MoO $\mathrm{M}_{3}$ nanocomposite.

structures the molybdenum oxides show Peierls transition. It is expected that the organic-inorganic nanocomposites made out of $\mathrm{MoO}_{3}$ and conducting polymer will show very good conducting properties. In addition to this, the material in nano-size should give us the opportunity of obtaining enhanced capacitance due to surface effects.

In this letter, we report a new and simple microwave assisted in situ intercalative polymerization reaction, which allows the intercalation of poly (3,4-ethylenedioxythiophene) nanosheets into the van der Waals gap of $\mathrm{MoO}_{3}$ to produce the nanocomposite. The application potential of this nanocomposite, displaying some unusual interesting effects with respect to enhancement of electrochemical supercapacitor and electrical properties of $\mathrm{MoO}_{3}$ by intercalation of PEDOT and the temperature dependence of conductivity were measured and discussed.

PEDOT- $\mathrm{MoO}_{3}$ nanocomposites were prepared by exfoliation of $50 \mathrm{mg}$ of lithium molybdenum bronze in $20 \mathrm{ml}$ of double distilled water, and after $1 \mathrm{~h}$ sonication to form a suspension with a concentration of $5 \mathrm{~g} \mathrm{l}^{-1}$. To this suspension 3,4-ethylenedioxythiophene (EDOT) monomer $(4.6 \mathrm{mM})$ was added dropwise and was stirred to ensure complete mixing. Subsequently, the required amount of iron (III) chloride $\left(\mathrm{FeCl}_{3}\right)$ as the oxidant which is dissolved in water was added dropwise to the suspension treated under microwave hydrothermal condition for $10 \mathrm{~min}, 950 \mathrm{~W}$ in a Teflon container. The final product was obtained by filtration and then washed with distilled water and ethanol several times.

Electronic conductivity was measured on compacted pellets using a four probe conductivity method. X-ray photoemission spectra (XPS) were recorded on VG Microtech Multilab ESCA 3000 spectrometer using a nonmonochromatized Al $K \alpha$ x-ray source $(h \nu=1486.6 \mathrm{eV})$. The base pressure in the chamber was maintained at the $10^{-10}$ Torr range. The energy resolution of the spectrometer was set at $1.0 \mathrm{eV}$ with Al $K \alpha$ radiation at a pass energy of $50 \mathrm{eV}$. Binding energy (BE) calibration was performed with the Au $4 f_{7 / 2}$ core level at $83.9 \mathrm{eV}$ and $\mathrm{BE}$ of adventitious carbon $(284.9 \mathrm{eV})$ was utilized for charging correction with all the samples. The error in all the $\mathrm{BE}$ values reported here is within $\pm 0.1 \mathrm{eV}$. The electrochemical measurements were carried out by the crystalline $\mathrm{MoO}_{3}$ and layered PEDOT- $\mathrm{MoO}_{3}$ nanocomposite, at several scan rates illustrating supercapacitor behavior usDownloaded 03 Jul 2006 to 147.210.60.241. Redistribution subjec

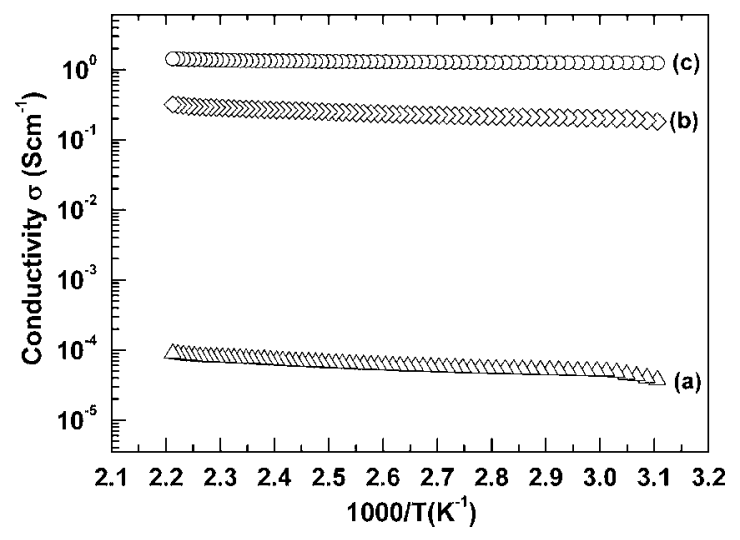

FIG. 2. Four-probe temperature dependence of electrical conductivity of (a) crystalline- $\mathrm{MoO}_{3}$; (b) PEDOT- $\mathrm{MoO}_{3}$ nanocomposite; and (c) PEDOT.

ing $1 \mathrm{M} \mathrm{LiClO}_{4}$ in EC/DMC $(1: 1 \mathrm{v} / \mathrm{v})$ in between $-1.5 \mathrm{~V}$ to $0.25 \mathrm{vs} \mathrm{Ag} / \mathrm{Ag}^{+}$reference electrode.

Since XPS is known to be very sensitive to the changes in electron density, it could be exploited well to study such changes in related organic-inorganic hybrid systems. ${ }^{15}$ XPS results for PEDOT and PEDOT/MoO $\mathrm{M}_{3}$ composites in terms of $\mathrm{S} 2 p, \mathrm{C} 1 s$, and Mo $3 d$ core levels are shown in Figs. $1(\mathrm{a})-1(\mathrm{c})$, respectively. More significantly, the $\mathrm{S} 2 p$ core level from PEDOT displays a peak at $164 \mathrm{eV}$, typical for thiophene sulfur. ${ }^{18}$ However, the $\mathrm{S} 2 p$ core level binding energy (BE) from PEDOT/MoO $\mathrm{M}_{3}$ shows a peak around $165 \mathrm{eV}$ suggesting charge transfer from sulfur atoms upon PEDOT intercalation. Carbon $1 s$ core level also shows similar changes before and after the intercalation. In sharp contrast, PEDOT shows a single but broad C $1 s$ peak at $285.3 \mathrm{eV}$, since the BE of carbon atoms from thiophene and ethylenedioxy groups are somewhat similar and hence are difficult to resolve. However upon intercalation, a broadening on the lower BE side and the appearance of a second peak are visible. The $\mathrm{C} 1 s$ peak around $286 \mathrm{eV}$ is attributed to the ethylenedioxy group and the lower BE peak at $284 \mathrm{eV}$ is attributed to the thiophene carbon atoms. The above shift in $\mathrm{C} 1 \mathrm{~s}$ $\mathrm{BE}$ of the thiophene group on intercalation suggests an increase in charge along with a broadening due to delocalization. In comparison, the ethylenedixoy groups remain at the same BE indicating that insignificant electronic involvement from this group. Mo $3 d_{5 / 2}$ core level at $232.5 \mathrm{eV}$ from PEDOT- $\mathrm{MoO}_{3}$ composite is typical for $\mathrm{MoO}_{3}$ (Ref. 18) and the XPS studies hint oxidation of PEDOT after intercalation into $\mathrm{MoO}_{3}$ along with some charge transfer from sulfur to $\mathrm{MoO}_{3}$.

The electron transport behavior of $\mathrm{MoO}_{3}$ is expected to be modified significantly by intercalation of PEDOT as the carrier density can undergo a dramatic change. Four probe dc-electronic conductivity of the PEDOT- $\mathrm{MoO}_{3}$ nanocomposite measured at variable temperature shows a linear increase in conductivity indicative of thermally activated electron transport with activation energy of $0.2 \mathrm{eV}$, which is shown in Fig. 2. The room temperature conductivity for the PEDOT- $\mathrm{MoO}_{3}$ composite is $1.82 \times 10^{-1} \mathrm{~S} \mathrm{~cm}^{-1}$, which is four orders of magnitude higher compared to that of the pristine $\mathrm{MoO}_{3}$. Consequently, the conductivity of PEDOT-MoO is therefore substantially higher than the room temperature conductivity of pristine $\mathrm{MoO}_{3}\left(3.78 \times 10^{-5} \mathrm{~S} \mathrm{~cm}^{-1}\right)$ and layered $\mathrm{Li}_{x} \mathrm{MoO}_{3}$, although it is less than that of bulk PEDOT
to AlP license or copyright, see http://apl.aip.org/apl/copyright.jsp 

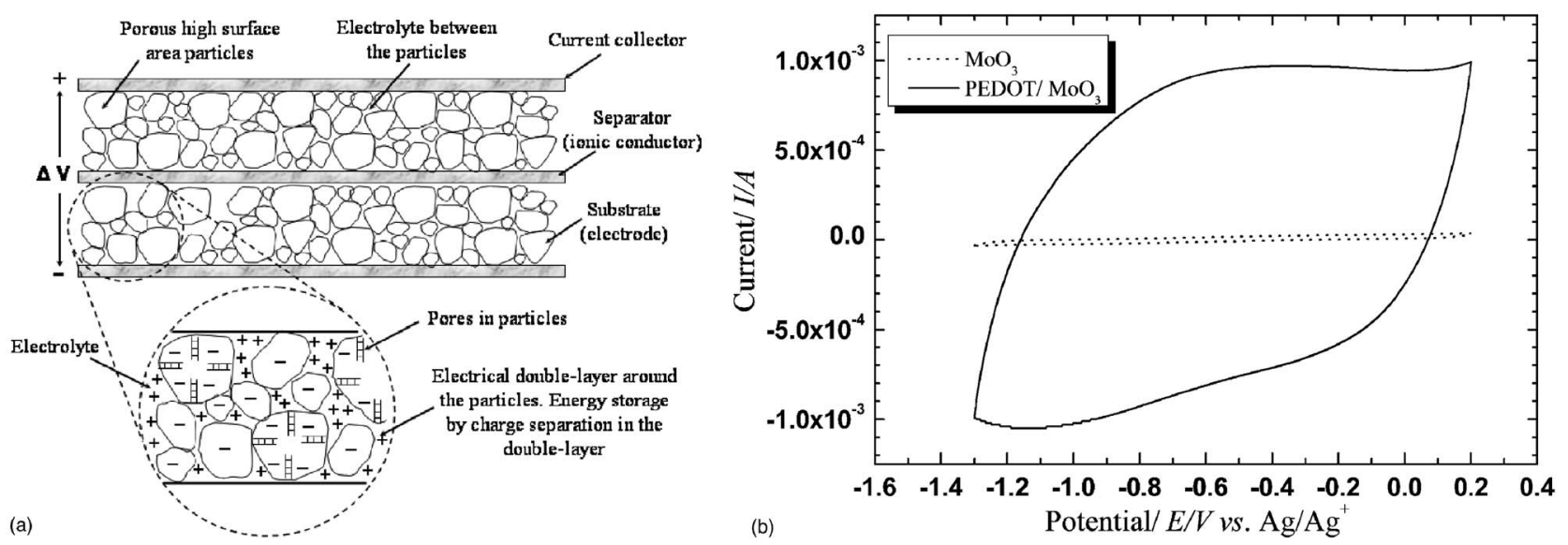

FIG. 3. (a). Schematic representation of an electric double-layer supercapacitor. Cyclic Voltammograms of (b) super imposed Cyclic Voltammogram of crystalline $\mathrm{MoO}_{3}$ and $\mathrm{PEDOT}-\mathrm{MoO}_{3}$ nanocomposite at $300 \mathrm{mV} \mathrm{s}{ }^{-1}$, illustrating the supercapacitor behavior using $1 \mathrm{M} \mathrm{LiClO}$ in EC/DMC (1:1 v/v).

$\left(\sim 1.248 \mathrm{~S} \mathrm{~cm}^{-1}\right)$. Similar electrical conductivity behavior for PANI- $\mathrm{MoO}_{3}$ hybrids has recently been reported. ${ }^{19}$

A schematic representation of an electrical double layer capacitor is shown in Fig. 3(a). In an electrochemical capacitor (ECC), (also known as supercapacitors or ultracapacitors), one can store a charge that is several hundred times more than that of a conventional capacitor, using an electrode-electrolyte interface. ${ }^{20}$ Comparative cyclic voltammograms of crystalline $\mathrm{MoO}_{3}$ and PEDOT- $\mathrm{MoO}_{3}$ at 300 $\mathrm{mV} \mathrm{s}^{-1}$ are shown in Fig. 3(b) using $1 \mathrm{M} \mathrm{LiClO}_{4}$ in $\mathrm{EC} /$ $\operatorname{DMC}(1: 1 \mathrm{v} / \mathrm{v})$ as the electrolyte, illustrating a drastic change in electrochemical properties induced by the polymer insertion. The observed linear current increase with scan rate is expected for a strongly adsorbed electrochemical species on the electrode surface. During the first cathodic scan, i.e., when the voltage changes from -1.5 to $0.25 \mathrm{~V}$ vs $\mathrm{Ag} / \mathrm{Ag}^{+}$, we observe the crystalline $\mathrm{MoO}_{3}$ undergoes a well-known phase transformation and the stabilization of this becomes more prominent after the fourth cycle, suggesting that the structural change is permanent. In contrast, for the PEDOT$\mathrm{MoO}_{3}$ hybrids, there is no sign of any irreversible structural change [Fig. 3(b)]; however, the broad cathodic peak, resembles that of $2 \mathrm{D}$ inorganic layered compounds. ${ }^{14}$ The broad and diffuse peak shape can, therefore, be correlated with the layer stacking derived by the polymer incorporation. It is interesting to note that the electrochemical double layer capacitance of pristine $\mathrm{MoO}_{3}$ increases from $\sim 40 \mathrm{~m} \mathrm{~F} \mathrm{~g}^{-1}$ to $\sim 300 \mathrm{~F} \mathrm{~g}^{-1}$ after a polymer intercalated into $\mathrm{MoO}_{3}$ as shown (super imposed) in Fig. 3(b).

In summary, we have employed a novel approach to prepare $\mathrm{PEDOT}-\mathrm{MoO}_{3}$ nanocomposite by using a microwave irradiated soft chemistry route. The XPS results show changes in electron density, while the shift in binding energy of the thiophene group on intercalation suggests an increase in charge along with a broadening due to delocalization. XPS studies also indicate that oxidation of PEDOT after intercalation into $\mathrm{MoO}_{3}$ along with some charge transfer from sulfur to $\mathrm{MoO}_{3}$. In addition, in the relative conductivity of PEDOT- $\mathrm{MoO}_{3}$ there is a four orders of magnitude increase compared to that of the pristine oxide. Significantly, the double layer electric capacitance of pristine $\mathrm{MoO}_{3}$ increases from $\sim 40 \mathrm{~m} \mathrm{~F} \mathrm{~g}^{-1}$ to $\sim 300 \mathrm{~F} \mathrm{~g}^{-1}$ after PEDOT incorporation into $\mathrm{MoO}_{3}$ under similar experimental conditions and the nanocomposite displays intriguing effects with respect to electrochemical $\mathrm{Li}^{+}$insertion. This results in a dramatic increase in the surface area and increase in electronic conductivity, which undoubtedly, improve the performance of the nanocomposite as a supercapacitor material. Thus PEDOT$\mathrm{MoO}_{3}$ nanocomposite appears to be a promising electrode material for nonaqueous type supercapacitors and this hybrid strategy pursued here provides an efficient and novel way to fabricate low cost supercapacitor electrodes.

${ }^{1}$ B. E. Conway, J. Electrochem. Soc. 138, 1539 (1991).

${ }^{2}$ Y. U. Jeong and A. Manthiram, J. Electrochem. Soc. 148, A189 (2001).

${ }^{3}$ A. K. Shukla, S. Sampath, and K. Vijayamohanan, Curr. Sci. 79, 12 (2000).

${ }^{4}$ S. Ghosh and O. Inganäs, Adv. Mater. (Weinheim, Ger.) 11, 1214 (1999).

${ }^{5}$ C. Downs, J. Nugent, P. M. Ajayan, D. J. Duquette, and K. S. V. Santhanam, Adv. Mater. (Weinheim, Ger.) 11, 1028 (1999).

${ }^{6}$ K. Jurewicz, S. Delpeux, V. Bertagna, F. Béguin, and E. Frackowiak, Chem. Phys. Lett. 347, 36 (2001).

${ }^{7}$ J. P. Zheng, Electrochem. Solid-State Lett. 2, 359 (1999).

${ }^{8}$ Y. Takasu, T. Nakamura, and Y. Murakami, Chem. Lett. 1998, 1215.

${ }^{9}$ G. Z. Chen, M. S. P. Shaffer, D. Coleby, G. Dixon, W. Zhou, D. J. Fray, and A. H. Windle, Adv. Mater. (Weinheim, Ger.) 12, 522 (2000).

${ }^{10}$ J. M. Miller and B. Dunn, Langmuir 15, 799 (1999).

${ }^{11}$ M. Hughes, G. Z. Chen, M. S. P. Shaffer, D. J. Fray, and A. H. Windle, Adv. Mater. (Weinheim, Ger.) 14, 1613 (2002).

${ }^{12}$ J.-I. Hong, I.-H. Yeo, W.-K. Paik, J. Electrochem. Soc. 148, A156 (2001).

${ }^{13}$ P. Novak, K. Muller, K. S. V. Santhanam, and O. Haas, Chem. Rev. (Washington, D.C.) 97, 207 (1997).

${ }^{14}$ P. Gomez-Romero, Adv. Mater. (Weinheim, Ger.) 13, 163 (2001).

${ }^{15}$ A. Vadivel Murugan, M. Quintin, M. H. Delville, G. Campet, and K. Vijayamohanan, J. Mater. Chem. 15, 902 (2005).

${ }^{16}$ V. Hernandez, F. J. Ramirez, T. F. Otero, and J. T. Lopez Navarrete, J. Chem. Phys. 100, 114 (1994).

${ }^{17}$ K. Eda, K. Chin, N. Sotani, and M. S. Whittingham, J. Solid State Chem. 178, 158 (2005).

${ }^{18}$ N. B. Colthup, L. H. Daly, and S. E. Wiberley, Introduction to Infrared and Raman Sectropcopy (Academic, New York, 1964), p. 276.

${ }^{19}$ L. Wang, J. Schindler, C. R. Kannewurf, and M. G. Kanatzidis, J. Mater. Chem. 7, 1277 (1997).

${ }^{20}$ A. Burke, J. Power Sources 91, 37 (2000). 